\title{
Mortality in severe sleep apnoea/hypopnoea syndrome patients: impact of treatment
}

\author{
S. Marti*, G. Sampol*, X. Muñoz*, F. Torres", A. Roca*, P. Lloberes*, T. Sagalés ${ }^{\natural}$, \\ P. Quesada ${ }^{+}$, F. Morell*
}

Mortality in severe sleep apnoealhypopnoea syndrome patients: impact of treatment. S. Marti, G. Sampol, X. Muñoz, F. Torres, A. Roca, P. Lloberes, T. Sagalés, P. Quesada, F. Morell. (C) ERS Journals Ltd 2002.

ABSTRACT: The aim of this study was to determine mortality in patients with sleep apnoea/hypopnoea syndrome (SAHS) according to the treatments employed and comorbidity.

An historical cohort of patients with SAHS diagnosed at a university hospital between 1982 and 1992 and followed until 1996 was studied. From a total of 475 SAHS patients, $444(94 \%)$, with a mean \pm SD apnoea/hypopnoea index at diagnosis of $55 \pm 27$, were located and included in the study. SAHS treatments employed were: surgery (88), weight loss (134), continuous positive airway pressure (124) and 98 patients were not treated.

By the end of follow-up, 49 patients had died. According to Cox regression analysis, mortality in treated patients was lower than in those not treated, but higher in those with a history of severe chronic obstructive pulmonary disease. Mortality in nontreated patients compared with that of the general population, adjusted for age and sex, showed excessive mortality, which decreased in treated patients. Stratification by age showed a greater mortality rate ratio in patients $<\mathbf{5 0}$ yrs. These findings were maintained when mortality from cardiovascular causes was compared.

In conclusion, a rise in mortality was found in nontreated sleep apnoea/hypopnoea syndrome patients compared with the general population, whereas mortality in those treated for sleep apnoea/hypopnoea syndrome did not differ significantly from that of the general population.

Eur Respir J 2002; 20: 1511-1518.
*Servei de Pneumologia, "Neurofisiologia Clínica and + Otorrinolaringologia, Hospital General Vall d'Hebron and ${ }^{*}$ Laboratori de Bioestadística i Epidemiologia, Universitat Autònoma de Barcelona, Barcelona, Spain.

Correspondence: S. Martí, Servei de Pneumologia, Hospital General Vall d'Hebron, Passeig Vall d'Hebron, 119-129, 08035 Barcelona, Spain. Fax: 34932746083

E-mail: smartib@hg.vhebron.es

Keywords: Cardiovascular diseases mortality

sleep apnoea syndrome

therapeutics

Received: January 42002

Accepted after revision: July 122002

This study was financed in part by a grant from Agència d'Avaluació de Tecnologia Mèdica (Servei Català de la Salut).
Sleep apnoea/hypopnoea syndrome (SAHS), with a prevalence $\sim 3 \%$ of the general population $[1,2]$, constitutes a major public health problem. It has been associated with a lack of normal nocturnal decrease in blood pressure [3] and the presence of diurnal systemic arterial hypertension (AHT) [4, 5]. Crosssectional studies have related SAHS to coronary heart disease [6,7] and stroke [8]. Sleep disruption and daytime sleepiness seen in SAHS patients also give rise to an increase in road accidents [9]. Other complications such as cor pulmonale [10] or respiratory failure [11] occur in some patients.

It has been postulated that the above-mentioned complications could account for the increased mortality observed in a reduced number of studies in clinical populations [12-14]. The availability of nasal continuous positive airway pressure (nCPAP) since the early 1980s [15], which is effective in improving symptoms and limiting apnoea/hypopnoea episodes [16], implies that it is not ethical to conduct long-term studies that involve random assignment of symptomatic patients to groups without treatment. The introduction of nCPAP into the current authors' centre in 1988 afforded a historical cohort of patients with severe SAHS, treated or not, in whom mortality in the long term was evaluated according to the treatment applied and comorbidity present at diagnosis. Furthermore, this mortality was compared with that of the general population used as an external control group.

\section{Patients and methods}

\section{Cohort recruitment}

All patients residing in Catalonia, Spain and diagnosed with SAHS between January 1982 and December 1992, in an out-patient department for sleep-disordered breathing of a university hospital (belonging to the National Health System (NHS), with universal coverage), were evaluated. The inclusion period for nontreated patients was considered closed in December 1987, since the advent of nCPAP in 1988 modified the characteristics of patients who remained untreated after this date. Patients $<16$ yrs, those treated by tracheostomy, or who presented 
hypothyroidism, acromegaly or malformations of the base of the skull were excluded from the study.

\section{Diagnosis}

Patients were referred to the clinic for suspected SAHS. They were assessed by a single physician (A. Roca); clinical history was recorded systematically and, if considered indicated, nocturnal polysomnography (PSG) was performed. The PSG collected the recordings of the electroencephalogram, electro-oculogram and chin electromyogram, electrocardiogram, oronasal airflow by thermistor and thoraco-abdominal movements. Arterial oxygen saturation $\left(\mathrm{Sa}_{\mathrm{a}} \mathrm{O}_{2}\right)$ throughout the night was monitored by an oxymeter, initially by an ear sensor (47201A; Hewlett Packard, Waltham, MA, USA) and later by digital pulsioximetry (Pulsox 7; Minolta, Schaffhausen, Switzerland). Sleep stages were interpreted according to the usually accepted criteria [17]: an apnoea was defined as the absence of airflow for at least $10 \mathrm{~s}$; and a hypopnoea was considered at any reduction $\geqslant 50 \%$ in oro-nasal flow, of at least $10 \mathrm{~s}$ duration, accompanied by a decrease in $\mathrm{S}_{\mathrm{a}} \mathrm{O}_{2}$. Finally, the apnoea/hypopnoea index (AHI) was defined as the number of apnoeas or hypopnoeas per hour of sleep. An AHI $\geqslant 10$ was considered diagnostic of SAHS.

\section{Treatment}

When the diagnosis of SAHS was established, and according to the PSG results, subjective symptoms and comorbidity, patients were offered the treatments available. 1) Hygienic dietary measures, consisting of a recommended diet of 1,000-1,500 kilocalories $\cdot \mathrm{day}^{-1}$, increased physical exercise, sleeping in the lateral decubitus position and avoidance of sedatives and alcohol. These measures, recommended in all patients, constituted the only treatment attempt in mild patients or those who rejected other treatments. Patients who received this treatment alone were considered as treated by diet or nontreated according to whether during the year following diagnosis they succeeded in losing $10 \%$ of their weight or not. 2) Uvulopalatopharyngoplastic surgery, performed in the Otorhinolaryngology Dept. The effects of diet or surgery were evaluated in a second PSG usually performed when a $10 \%$ weight loss had been achieved or at 6 months postsurgery. 3) nCPAP, available at the current authors' centre since 1988, which has become the treatment of choice for moderate-to-severe SAHS [18]. In patients for whom this treatment was considered to be indicated, a second nocturnal PSG was performed to determine the pressure level required to suppress apnoeas, hypopnoeas and snoring. If $\mathrm{Sa}_{\mathrm{a}} \mathrm{O}_{2}<90 \%$ persisted when effective pressures were reached, oxygen was added to the nCPAP mask at a flow required to achieve saturations $>90 \%$. The apparatus was provided and its technical servicing carried out in the patients' home by the supplying company, with the costs covered by the NHS. Subjective compliance reported by the patient at the latest visit was recorded.

\section{Follow-up}

Patients were included from the time of SAHS diagnosis and the follow-up was closed in December 1996. In patients who abandoned the initial treatment before this date, follow-up was ended at that time and the information generated up to that point was used. Clinical follow-up consisted of medical appointments at 1, 3 and 6 months postdiagnosis, and every 6 months thereafter.

Information on the follow-up period was obtained by personal interview in the out-patient department, telephone or mail. If a patient had died, the next of kin was contacted. In order to obtain information on all deceased patients or those not located, data from the Mortality Registry of Catalonia (MRC; Servei d'Informació i Estudis, Direcció General de Recursos Sanitaris, Dept de Sanitat i Seguretat Social) for 1982-1996 was used, which provided the basic causes of death classified into four groups: 1) cardiovascular causes (International Classification of Diseases (ICD)9 codes [19] 390-459, 798); 2) accidents (ICD-9 codes 800-869, 880-901, 904-906, 910-921, 924-926, 928); 3) respiratory causes (ICD-9 codes 460-519, 786); and 4) others. For labelling of the causes of death, those stated in the clinical history or reported by the relative were considered first, and causes reported by the MRC were considered only in cases not located by other routes. Patients not located by any of the cited routes were not considered in later analyses. The selection and location of patients are depicted in figure 1 .

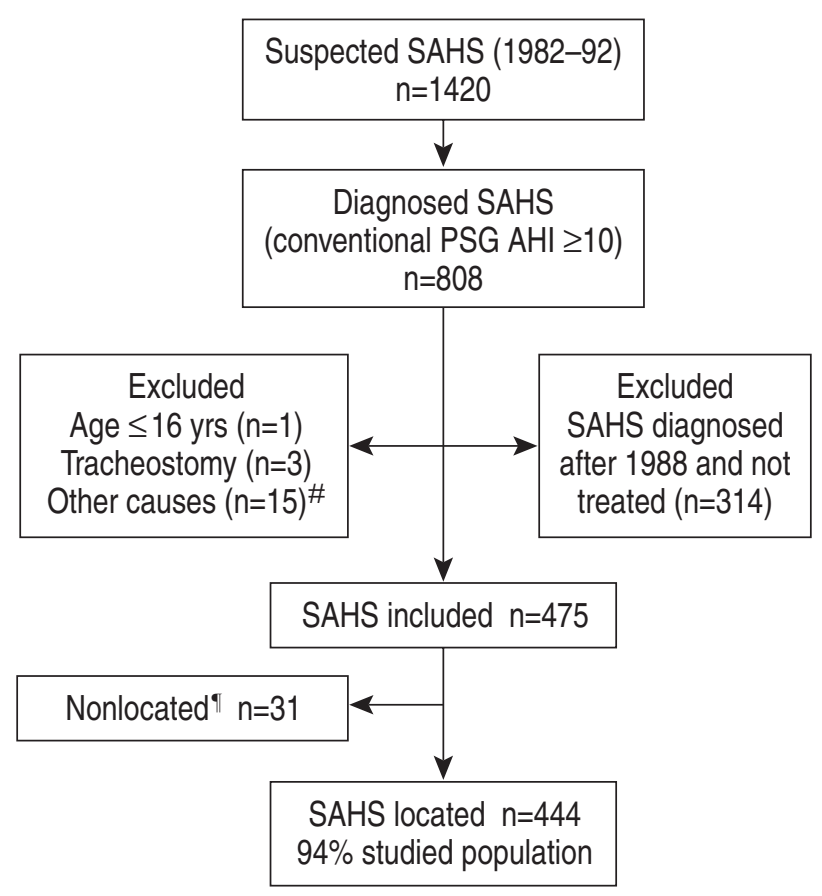

Fig. 1.-Selection of sleep apnoea/hypopnoea syndrome (SAHS) patient cohort. PSG: polysomnography; AHI: apnoea/hypopnoea index. \#: hypothyroidism $(n=10)$, acromegaly $(n=4)$ and ArnoldChiari malformation $(n=1)$; $:$ the treatments received by nonlocated patients were: surgery $(n=5)$, weight loss $(n=18)$, continuous positive airway pressure $(n=3)$ and nontreated $(n=5)$. 
Analysis

Descriptive and bivariate statistical analysis was performed in the first phase. Independent variables analysed in this phase were: age, sex, body mass index (BMI), alcohol consumption and smoking history, AHT, coronary heart disease, stroke, diabetes mellitus, dyslipaemia, chronic obstructive pulmonary disease (COPD), AHI, SAHS treatment and compliance with nCPAP treatment. Tests used were t-test or analysis of variance for continuous variables and Chi-squared for qualitative variables. When the application conditions were not met, Mann-Whitney, Kruskal-Wallis or Fisher's exact test, respectively, were used. Results were expressed as mean \pm SD for quantitative variables and as percentage for qualitative variables. The Kaplan-Meier method of survival analysis was applied for calculation of survival rates.

In the multivariate phase, the Cox proportional risk model was used to determine the predictive variables of mortality [20]. A series of variables of particular interest was selected or "forced" as fixed in the model, and the rest were added one by one and their effect on the predetermined model was evaluated. The independent variables for this phase were selected in accordance with the bivariate analysis $(p<0.10)$ or for being considered biologically plausible. Results of Cox regression were expressed as hazard ratio $(95 \%$ confidence interval (CI)). Patients who left the initial treatment cohort were considered censored at the time of withdrawal. SAHS-related mortality was considered to be that due to cardiovascular or respiratory causes or accidents. Patients who died of other causes were treated as censored in the analysis of SAHSrelated mortality.

Mortality rates of the cohort were compared with those of the general population of Catalonia from 1982 to 1996, as an external control group. For this, the MRC provided the causes of death in the cited period and the population in the 1991 census of Catalonia was considered [21]. Specific mortality rates were calculated, according to the cause of death, by age and sex, using Poisson regression and the person-year method [20], and compared with the number of deaths observed. The linear trend in the risk was evaluated for the age variable. Taking into account the effect of age on mortality, this analysis underlines the real prognostic impact of age.

Two-tailed $\mathrm{p}$-values of $<0.05$ were considered significant.

\section{Results}

\section{Baseline characteristics}

The population studied consisted of 444 patients with SAHS, of whom 389 were males $(88 \%)$, age $53 \pm 10 \mathrm{yrs}$, BMI $32 \pm 5 \mathrm{~kg} \cdot \mathrm{m}^{-2}$ and AHI at diagnosis $55 \pm 27$. The patients were referred for consultation by a general practitioner $(23 \%)$, ear, nose and throat specialist $(29 \%)$, pneumologist $(26 \%)$ or other specialists $(22 \%)$. Many of the patients had associated comorbidity at diagnosis of SAHS: AHT (43\%), coronary heart disease $(7 \%)$, stroke $(2 \%)$, diabetes mellitus ( $8 \%$ ), dyslipaemia $(19 \%)$ and COPD (27\%). No significant differences were observed when all the previously cited characteristics in patients studied were compared with those of nonlocated patients $(\mathrm{n}=31)$. Eighty-eight patients were treated by surgery, 134 by diet and 124 by nCPAP, while 98 received no treatment. The baseline characteristics, grouped according to treatment cohort, are shown in table 1. The surgically treated group were younger and had lower BMI and history of AHT and COPD than the other treatment groups.

\section{Follow-up}

Mean follow-up of the different cohorts was $7.1 \pm 2.0$ yrs in surgery, $7.2 \pm 2.4$ diet, 5.2 $\pm 1.9 \mathrm{nCPAP}$ and 7.2 \pm 3.1 in those nontreated. Control PSG was performed in 75 patients treated with surgery $(85 \%$ of those belonging to this cohort), with AHI of $22 \pm 22$ (AHI at diagnosis $58 \pm 26 ; \mathrm{p}<0.001) ; 29$ patients $(33 \%$

Table 1.-Baseline characteristics of sleep apnoea/hypopnoea syndrome patients according to treatment group

\begin{tabular}{|c|c|c|c|c|c|}
\hline & Surgery & Diet & CPAP & Nontreated & p-value \\
\hline Patients $\mathrm{n}$ & 88 & 134 & 124 & 98 & \\
\hline Sex males $\%$ & 90 & 89 & 86 & 86 & $>0.20$ \\
\hline Age yrs & $50 \pm 10$ & $52 \pm 9$ & $54 \pm 9$ & $54 \pm 10$ & 0.006 \\
\hline $\mathrm{BMI} \mathrm{kg} \cdot \mathrm{m}^{-2}$ & $28 \pm 3$ & $32 \pm 4$ & $33 \pm 5$ & $33 \pm 6$ & $<0.001$ \\
\hline Smoking \% & 70 & 62 & 72 & 76 & 0.10 \\
\hline \multicolumn{6}{|l|}{ History $\%$} \\
\hline AHT & 27 & 45 & 39 & 58 & $<0.001$ \\
\hline CHD & 3 & 5 & 10 & 8 & 0.12 \\
\hline Stroke & 1 & 1 & 2 & 4 & $>0.20$ \\
\hline \multicolumn{6}{|l|}{ COPD } \\
\hline $\mathrm{FEV}_{1} \geqslant 50 \%$ pred & 15 & 20 & 18 & 20 & 0.03 \\
\hline FEV $1<50 \%$ pred & 2 & 5 & 11 & 13 & \\
\hline AHI & $58 \pm 27$ & $53 \pm 27$ & $57 \pm 22$ & $50 \pm 31$ & 0.01 \\
\hline
\end{tabular}

Data are presented as mean \pm SD unless otherwise stated. CPAP: continuous positive airway pressure; BMI: body mass index; AHT: arterial hypertension; CHD: coronary heart disease; COPD: chronic obstructive pulmonary disease; FEV1: forced expiratory volume in one second, expressed as \% of the predicted value; AHI: apnoea/hypopnoea index. 

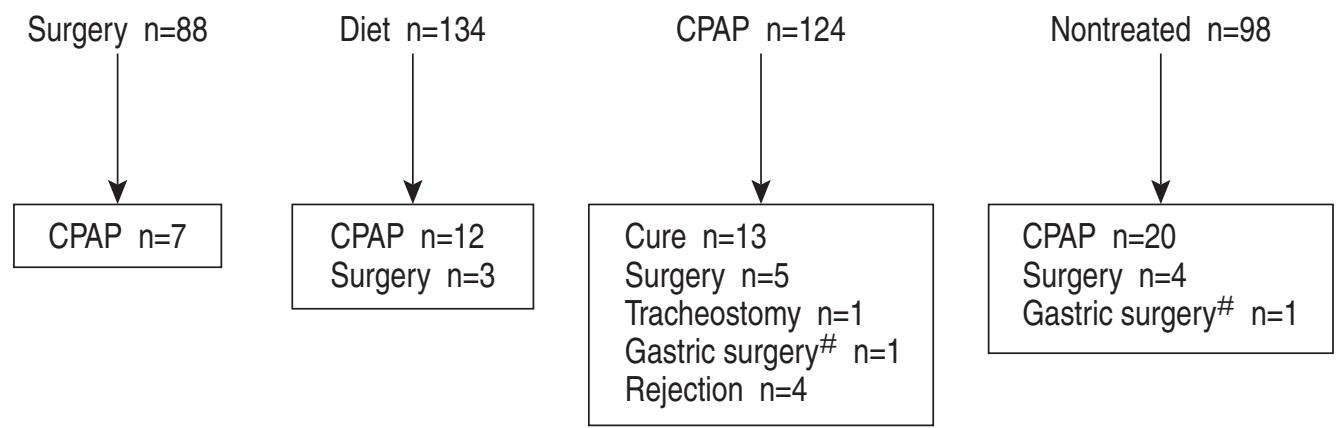

Fig. 2. - Patients leaving their original treatment cohort before the end of follow-up. CPAP: continuous positive airway pressure. ${ }^{\#}$ : gastric surgery as treatment for obesity.

of those surgically treated) were cured of SAHS (AHI $<10$ on control PSG). Similarly, a second PSG was performed approximately $1 \mathrm{yr}$ after diagnosis in 112 treated with diet $\left(84 \%\right.$; BMI $27 \pm 3$ versus $32 \pm 4 \mathrm{~kg} \cdot \mathrm{m}^{-2}$ at diagnosis; $\mathrm{p}<0.001)$ with AHI $24 \pm 26(54 \pm 27$ at diagnosis; $\mathrm{p}<0.001)$; cure of SAHS was recorded in 49 patients $(37 \%)$. At the end of the follow-up, BMI in those treated with surgery or diet was $27 \pm 3$ and $30 \pm 4 \mathrm{~kg} \cdot \mathrm{m}^{-2}$, respectively. Subjective compliance with nCPAP treatment was $6.9 \pm 1.7 \mathrm{~h} \cdot \mathrm{day}^{-1} ; 85 \%$ of patients reported compliance of at least $6 \mathrm{~h}$. The follow-up was closed before December 1996 owing to change of the initial treatment cohort in 71 out of the 444 patients (fig. 2).

\section{Mortality}

By the end of follow-up, 49 patients had died $(11 \%)$. Their mean age at the time of diagnosis was $55 \pm 11 \mathrm{yrs}, 42$ were males, BMI $33 \pm 7 \mathrm{~kg} \cdot \mathrm{m}^{-2}$ and AHI $53 \pm 30$. The causes of death are detailed in table 2. Survival rate at 5 yrs for nontreated patients was 0.80 (CI 95\% 0.72-0.88), while in those treated with surgery, diet or nCPAP it was $1,0.97(0.94-0.99)$ and $0.97(0.94-1.00)$, respectively. Figure 3 depicts the Kaplan-Meier survival curve for patients treated or nontreated.

Multivariate analysis by Cox regression, to find predictive factors of overall and SAHS-related mortality,

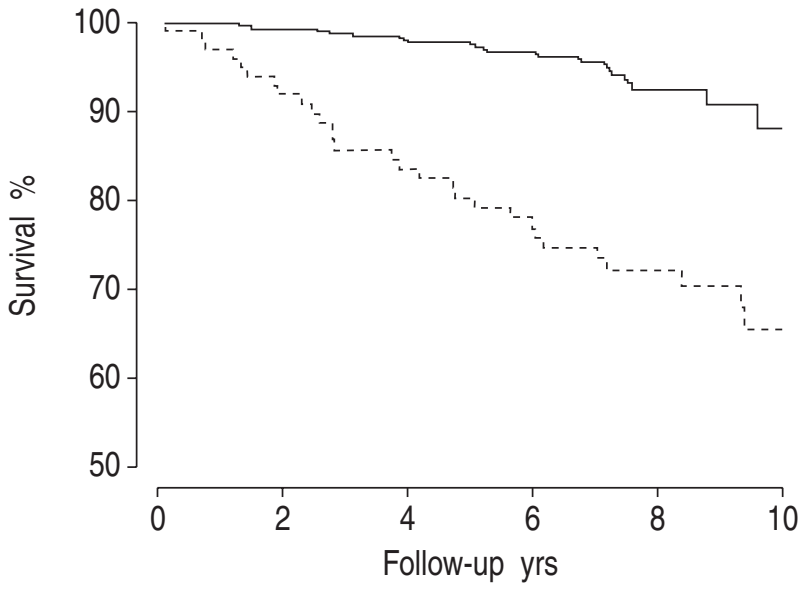

Fig. 3.-Kaplan-Meier estimate of the survival curve for sleep apnoea/hypopnoea syndrome patients, according to whether they were treated (-) or nontreated (---).

showed a reduction with the different treatments applied, but an increase with a history of severe COPD (tables 3 and 4). For instance, nCPAP treatment (hazard ratio 0.23 , CI 95\% $0.09-0.58$ ) led to a reduction in mortality compared with nontreated patients of at least $40 \%$, when the upper limit of the $95 \%$ CI was considered. These results were maintained even when coronary heart disease, smoking and COPD were taken into account. A trend towards increased SAHS-related mortality was also observed

Table 2. - Causes of death in sleep apnoea/hypopnoea syndrome patients, grouped according to treatment

\begin{tabular}{|c|c|c|c|c|c|}
\hline Cause & Surgery & Diet & CPAP & Nontreated & Subjects n $(\%)$ \\
\hline Acute myocardial infarction & & 4 & & 6 & $10(21)$ \\
\hline Stroke & & & 1 & 2 & $3(6)$ \\
\hline Sudden death & & 1 & 1 & 1 & $3(6)$ \\
\hline Other cardiovascular ${ }^{\#}$ & & 1 & & 2 & $3(6)$ \\
\hline Respiratory & & 1 & 2 & 6 & $9(18)$ \\
\hline Traffic accidents & & & & 2 & $2(4)$ \\
\hline Neoplasias & 3 & 2 & 1 & 4 & $10(21)$ \\
\hline Others $^{+}$ & & 1 & 1 & 7 & $9(18)$ \\
\hline Total n (\%) & $3(6)$ & $10(21)$ & $6(12)$ & $30(61)$ & $49(100)$ \\
\hline
\end{tabular}

CPAP: continuous positive airway pressure. ${ }^{\#}$ : includes one death from heart failure and two provided by the Mortality Registry (MR); ${ }^{\uparrow}$ : three deaths from respiratory failure in the postoperative period, three from chronic respiratory failure in chronic obstructive pulmonary disease patients and three provided by the MR; ${ }^{+}:$three deaths due to choking, suicide and chronic renal failure and six provided by the MR. 
Table 3. - Cox regression: overall mortality

\begin{tabular}{|c|c|c|c|c|c|c|}
\hline \multirow[t]{2}{*}{ Variable } & \multirow[t]{2}{*}{ Original model } & \multicolumn{5}{|c|}{ Added variable } \\
\hline & & CHD history & COPD history & Sex & Smoking & AHI \\
\hline \multicolumn{7}{|l|}{ Age } \\
\hline$<50$ yrs & 1.00 & 1.00 & 1.00 & 1.00 & 1.00 & 1.00 \\
\hline $50-60$ yrs & $\begin{array}{c}1.50 \\
(0.71-3.16)\end{array}$ & $\begin{array}{c}1.52 \\
(0.72-3.20)\end{array}$ & $\begin{array}{c}1.50 \\
(0.71-3.18)\end{array}$ & $\begin{array}{c}1.52 \\
(0.72-3.21)\end{array}$ & $\begin{array}{c}1.58 \\
(0.74-3.34)\end{array}$ & $\begin{array}{c}1.54 \\
(0.73-3.24)\end{array}$ \\
\hline$>60 \mathrm{yrs}$ & $\begin{array}{c}3.02 \\
(1.41-6.48)^{*}\end{array}$ & $\begin{array}{c}2.99 \\
(1.39-6.43)^{*}\end{array}$ & $\begin{array}{c}2.48 \\
(1.13-5.46)^{*}\end{array}$ & $\begin{array}{c}3.29 \\
(1.51-7.16)^{*}\end{array}$ & $\begin{array}{c}3.50 \\
(1.61-7.59)^{*}\end{array}$ & $\begin{array}{c}3.20 \\
(1.48-6.92)^{*}\end{array}$ \\
\hline \multicolumn{7}{|l|}{ BMI } \\
\hline$<28 \mathrm{~kg} \cdot \mathrm{m}^{-2}$ & 1.00 & 1.00 & 1.00 & 1.00 & 1.00 & 1.00 \\
\hline $28-35 \mathrm{~kg} \cdot \mathrm{m}^{-2}$ & $\begin{array}{c}1.12 \\
(0.46-2.70)\end{array}$ & $\begin{array}{c}1.13 \\
(0.47-2.72)\end{array}$ & $\begin{array}{c}1.14 \\
(0.47-2.77)\end{array}$ & $\begin{array}{c}1.11 \\
(0.46-2.67)\end{array}$ & $\begin{array}{c}1.08 \\
(0.45-2.60)\end{array}$ & $\begin{array}{c}1.09 \\
(0.45-2.63)\end{array}$ \\
\hline$>35 \mathrm{~kg} \cdot \mathrm{m}^{-2}$ & $\begin{array}{c}1.84 \\
(0.71-4.78)\end{array}$ & $\begin{array}{c}1.89 \\
(0.72-4.95)\end{array}$ & $\begin{array}{c}1.88 \\
(0.71-4.95)\end{array}$ & $\begin{array}{c}2.02 \\
(0.77-5.34)\end{array}$ & $\begin{array}{c}2.02 \\
(0.78-5.24)\end{array}$ & $\begin{array}{c}1.77 \\
(0.67-4.63)\end{array}$ \\
\hline \multicolumn{7}{|l|}{ AHT history } \\
\hline No & 1.00 & 1.00 & 1.00 & 1.00 & 1.00 & 1.00 \\
\hline Yes & $\begin{array}{c}1.06 \\
(0.58-1.94)\end{array}$ & $\begin{array}{c}1.04 \\
(0.56-1.91)\end{array}$ & $\begin{array}{c}1.18 \\
(0.63-2.22)\end{array}$ & $\begin{array}{c}1.09 \\
(0.59-2.00)\end{array}$ & $\begin{array}{c}1.16 \\
(0.63-2.12)\end{array}$ & $\begin{array}{c}1.05 \\
(0.57-1.93)\end{array}$ \\
\hline \multicolumn{7}{|l|}{ SAHS treatment } \\
\hline No & 1.00 & 1.00 & 1.00 & 1.00 & 1.00 & 1.00 \\
\hline Surgery & $\begin{array}{c}0.15 \\
(0.04-0.53)^{*}\end{array}$ & $\begin{array}{c}0.16 \\
(0.04-0.54)^{*}\end{array}$ & $\begin{array}{c}0.19 \\
(0.05-0.65)^{*}\end{array}$ & $\begin{array}{c}0.16 \\
(0.04-0.57)^{*}\end{array}$ & $\begin{array}{c}0.17 \\
(0.05-0.59)^{*}\end{array}$ & $\begin{array}{c}0.14 \\
(0.04-0.50)^{*}\end{array}$ \\
\hline Diet & $\begin{array}{c}0.26 \\
(0.12-0.54)^{*}\end{array}$ & $\begin{array}{c}0.26 \\
(0.12-0.55)^{*}\end{array}$ & $\begin{array}{c}0.28 \\
(0.13-0.59) *\end{array}$ & $\begin{array}{c}0.26 \\
(0.12-0.54) *\end{array}$ & $\begin{array}{c}0.28 \\
(0.13-0.58) *\end{array}$ & $\begin{array}{c}0.25 \\
(0.12-0.52) *\end{array}$ \\
\hline \multirow[t]{2}{*}{ CPAP } & 0.23 & 0.23 & 0.25 & 0.23 & 0.24 & 0.22 \\
\hline & $(0.09-0.58)^{*}$ & $(0.09-0.58)^{*}$ & $(0.10-0.62) *$ & $(0.09-0.59)^{*}$ & $(0.09-0.60)^{*}$ & $(0.08-0.55)^{*}$ \\
\hline \multirow[t]{3}{*}{ Added variable } & & 1.00 & 1.00 & 1.00 & 1.00 & 1.00 \\
\hline & & 1.31 & 1.50 & 1.51 & 2.02 & 0.71 \\
\hline & & $(0.50-3.40)$ & $\begin{array}{c}(0.71-3.13)^{\top} \\
2.62 \\
(1.20-5.69)^{*,+}\end{array}$ & $(0.63-3.60)$ & $(0.98-4.18)^{\#}$ & $(0.33-1.50)$ \\
\hline
\end{tabular}

Data are presented as hazard ratio (95\% confidence interval). CHD: coronary heart disease; COPD: chronic obstructive pulmonary disease; AHI: apnoea/hypopnoea index; BMI: body mass index; AHT: arterial hypertension; SAHS: sleep apnoea/ hypopnoea syndrome; CPAP: continuous positive airway pressure. ${ }^{*}: \mathrm{p}<0.05$; ${ }^{\#}: \mathrm{p}<0.10$ and $\geqslant 0.05$. Reference categories of variables added to the original model: no CHD history, no COPD history, female sex, no smoking habit and AHI $\geqslant 30$; ?: COPD history forced expiratory volume in one second (FEV1) $\geqslant 50 \%$; ${ }^{+}$: COPD history FEV $1<50 \%$.

with $\mathrm{BMI}>35 \mathrm{~kg} \cdot \mathrm{m}^{-2}$. Sex, AHI and AHT history did not influence the adjusted models. Even when AHI was analysed exclusively in nontreated SAHS patients, no relationship was found with mortality $(\mathrm{p}>0.20)$.

The overall mortality rates observed in nontreated SAHS patients compared with those expected in the general population, adjusted for age and sex, showed excessive mortality (table 5), both in males (rate ratio (RR) 4.58, CI 95\% 3.09-6.78) and females (RR 8.07, CI 95\% 2.09-31.19). Stratification by ages performed only in males, given the scant number of deceased females, reflected an increase in mortality RR in the youngest patients that decreased progressively with age, although it remained high in those $>60 \mathrm{yrs}$. In contrast, when treated SAHS patients were analysed, overall mortality rates decreased and were somewhat higher compared with those calculated for the general population, though without reaching a statistically significant difference (RR 1.29, CI 95\% 0.80-2.07 in males; RR 1.11, CI 95\% 0.16-7.70 in females). These trends were maintained when SAHS-related (data not shown) and cardiovascular mortality rates (table 6) were compared.

\section{Discussion}

The present study, conducted in a clinical severe SAHS cohort, showed that patients with untreated SAHS presented higher mortality than the general population, adjusted for age and sex. Given the wide CI shown by the mortality rate ratios, the lower limit of these intervals can be considered the minimum risk consistent with the present data. Thus, the relative risk of mortality presented by patients with nontreated SAHS would be at least in the order of 2-3 times that of the general population. As in previous works, the excess of mortality detected was basically due to cardiovascular [13, 14, 22, 23] and respiratory [22] causes, which have been related to SAHS. Conversely, when SAHS patients were treated by surgery, weight loss or nCPAP, mortality was similar to that of the general population. This lower mortality observed in patients with treated SAHS persisted once other possible confounders had been adjusted by Cox regression.

Certain considerations should be borne in mind regarding the design of the present study. First, there may have been a selection bias; nevertheless, the 
Table 4.-Cox regression: sleep apnoea/hypopnoea syndrome-related mortality

\begin{tabular}{|c|c|c|c|c|c|c|}
\hline \multirow[t]{2}{*}{ Variable } & \multirow{2}{*}{$\begin{array}{l}\text { Original } \\
\text { model }\end{array}$} & \multicolumn{5}{|c|}{ Added variable } \\
\hline & & CHD history & COPD history & Sex & Smoking & AHI \\
\hline \multicolumn{7}{|l|}{ Age } \\
\hline$<50$ yrs & 1.00 & 1.00 & 1.00 & 1.00 & 1.00 & 1.00 \\
\hline $50-60$ yrs & $\begin{array}{l}0.65 \\
058)\end{array}$ & 0.67 & $\begin{array}{c}0.64 \\
(024-165)\end{array}$ & $\begin{array}{c}0.66 \\
(0.5-170)\end{array}$ & $\begin{array}{c}0.69 \\
0.6-177)\end{array}$ & $\begin{array}{c}0.68 \\
06-174)\end{array}$ \\
\hline$>60 \mathrm{yrs}$ & $\begin{array}{c}(0.25-1.68) \\
2.14 \\
(0.91-5.04)^{\#}\end{array}$ & $\begin{array}{c}(0.26-1.74) \\
2.09 \\
(0.88-4.95)^{\#}\end{array}$ & $\begin{array}{c}(0.24-1.65) \\
1.65 \\
(0.67-4.05)\end{array}$ & $\begin{array}{c}(0.25-1.70) \\
2.31 \\
(0.96-5.57)^{\#}\end{array}$ & $\begin{array}{c}(0.26-1.77) \\
2.45 \\
(1.02-5.87)^{*}\end{array}$ & $\begin{array}{c}(0.26-1.74) \\
2.36 \\
(0.99-5.62)^{\#}\end{array}$ \\
\hline \multicolumn{7}{|l|}{ BMI } \\
\hline$<28 \mathrm{~kg} \cdot \mathrm{m}^{-2}$ & 1.00 & 1.00 & 1.00 & 1.00 & 1.00 & 1.00 \\
\hline $28-35 \mathrm{~kg} \cdot \mathrm{m}^{-2}$ & 1.94 & 1.99 & 2.43 & 1.90 & 1.86 & 1.93 \\
\hline & $(0.43-8.66)$ & $(0.45-8.88)$ & $(0.53-11.14)$ & $(0.42-8.45)$ & $(0.42-8.26)$ & $(0.43-8.60)$ \\
\hline$>35 \mathrm{~kg} \cdot \mathrm{m}^{-2}$ & $\begin{array}{c}3.48 \\
(0.74-16.21)\end{array}$ & $\begin{array}{c}3.72 \\
(0.79-17.41)^{\#}\end{array}$ & $\begin{array}{c}4.01 \\
(0.83-19.37)^{\#}\end{array}$ & $\begin{array}{c}3.75 \\
(0.80-17.57)^{\#}\end{array}$ & $\begin{array}{c}3.70 \\
(0.79-17.14)^{\#}\end{array}$ & $\begin{array}{c}3.39 \\
(0.72-15.95)\end{array}$ \\
\hline \multicolumn{7}{|l|}{ AHT history } \\
\hline No & 1.00 & 1.00 & 1.00 & 1.00 & 1.00 & 1.00 \\
\hline Yes & $\begin{array}{c}1.25 \\
(0.57-2.73)\end{array}$ & $\begin{array}{c}1.20 \\
(0.55-2.64)\end{array}$ & $\begin{array}{c}1.32 \\
(0.58-2.98)\end{array}$ & $\begin{array}{c}1.30 \\
(0.59-2.84)\end{array}$ & $\begin{array}{c}1.36 \\
(0.62-2.99)\end{array}$ & $\begin{array}{c}1.20 \\
(0.54-2.65)\end{array}$ \\
\hline \multicolumn{7}{|l|}{ SAHS treatment } \\
\hline No & 1.00 & 1.00 & 1.00 & 1.00 & 1.00 & 1.00 \\
\hline Surgery & $\approx 0^{*}$ & $\approx 0 *$ & $\approx 0^{*}$ & $\approx 0^{*}$ & $\approx 0^{*}$ & $\approx 0 *$ \\
\hline \multirow[t]{2}{*}{ Diet } & 0.25 & 0.26 & 0.28 & 0.25 & 0.26 & 0.23 \\
\hline & $(0.10-0.61)^{*}$ & $(0.10-0.64)^{*}$ & $(0.11-0.68)^{*}$ & $(0.10-0.61)^{*}$ & $(0.11-0.64)^{*}$ & $(0.09-0.56)^{*}$ \\
\hline \multirow[t]{2}{*}{ CPAP } & 0.22 & 0.22 & 0.24 & 0.22 & 0.23 & 0.20 \\
\hline & $(0.07-0.68)^{*}$ & $(0.07-0.68)^{*}$ & $(0.08-0.74)^{*}$ & $(0.07-0.69)^{*}$ & $(0.07-0.70)^{*}$ & $(0.06-0.62)^{*}$ \\
\hline \multirow[t]{3}{*}{ Added variable } & & 1.00 & 1.00 & 1.00 & 1.00 & 1.00 \\
\hline & & 1.70 & 1.21 & 1.43 & 1.78 & 0.50 \\
\hline & & $(0.57-5.08)$ & $\begin{array}{c}(0.44-3.32)^{\bullet} \\
3.37(1.34-8.48)^{*,+}\end{array}$ & $(0.50-4.08)$ & $(0.73-4.35)$ & $(0.15-1.47)$ \\
\hline
\end{tabular}

Data are presented as hazard ratio (95\% confidence interval). CHD: coronary heart disease; COPD: chronic obstructive pulmonary disease; AHI: apnoea/hypopnoea index; BMI: body mass index; AHT: arterial hypertension; SAHS: sleep apnoea/ hypopnoea syndrome; CPAP: continuous positive airway pressure. ${ }^{*}: \mathrm{p}<0.05 ;{ }^{\#}: \mathrm{p}<0.10$ and $\geqslant 0.05$. Reference categories of variables added to the original model: no CHD history, female sex, no smoking habit and AHI $\geqslant 30$. ${ }^{\circ}$. COPD history forced expiratory volume in one second $(\mathrm{FEV} 1) \geqslant 50 \% ;^{+}$: COPD history FEV $1<50 \%$.

distribution of age at diagnosis $(53 \pm 10 \mathrm{yrs})$ and sex (88\% males), similar to that of other clinical cohorts reported in the literature, supports the representative

Table 5. - Observed and expected overall mortality, adjusted for age and sex, rate ratio (RR) and $95 \%$ confidence interval $(\mathrm{Cl})$

\begin{tabular}{lccrc}
\hline & Observed & Expected & $\mathrm{RR}$ & $95 \% \mathrm{CI}$ \\
\hline Nontreated SAHS & & & & \\
$\quad$ Sex & & & & \\
$\quad$ Males & 25 & 5.46 & 4.58 & $3.09-6.78$ \\
$\quad$ Females & 5 & 0.62 & 8.07 & $2.09-31.19$ \\
Age in males & & & & \\
$\quad$ 17-50 yrs & 4 & 0.25 & 16.06 & $6.03-42.80$ \\
51-60 yrs & 8 & 1.35 & 5.95 & $2.97-11.89$ \\
$\quad>60$ yrs & 13 & 3.87 & 3.36 & $1.95-5.79$ \\
Test for trend & & & & $\mathrm{p}=0.02$ \\
Treated SAHS & & & & \\
Sex & & & & \\
$\quad$ Males & 17 & 13.20 & 1.29 & $0.80-2.07$ \\
$\quad$ Females & 2 & 1.81 & 1.11 & $0.16-7.70$ \\
Age in males & & & & \\
$\quad$ 17-50 yrs & 1 & 1.42 & 0.71 & $0.10-5.01$ \\
$\quad 51-60$ yrs & 6 & 4.45 & 1.35 & $0.61-3.00$ \\
$\quad>60$ yrs & 10 & 7.33 & 1.36 & $0.73-2.53$ \\
Test for trend & & & & $\mathrm{p}>0.20$ \\
\hline
\end{tabular}

SAHS: sleep apnoea/hypopnoea syndrome. nature of the present cohort. Secondly, the treatments were not randomly distributed among the patients. This may have given rise to differences among the

Table 6. - Observed and expected cardiovascular mortality, adjusted for age and sex, rate ratio (RR) and $95 \%$ confidence interval $(\mathrm{Cl})$

\begin{tabular}{|c|c|c|c|c|}
\hline & Observed & Expected & RR & $95 \% \mathrm{CI}$ \\
\hline \multicolumn{5}{|l|}{ Nontreated SAHS } \\
\hline \multicolumn{5}{|l|}{ Sex } \\
\hline Males & 11 & 1.54 & 7.15 & $3.96-12.91$ \\
\hline Females & 0 & 0.21 & 0 & 0 -infinite \\
\hline \multicolumn{5}{|l|}{ Age in males } \\
\hline $17-50$ yrs & 1 & 0.05 & 20.92 & $2.95-148.55$ \\
\hline $51-60$ yrs & 4 & 0.34 & 11.72 & $4.40-31.23$ \\
\hline$>60$ yrs & 6 & 1.15 & 5.22 & $2.34-11.62$ \\
\hline Test for trend & & & & $\mathrm{p}=0.13$ \\
\hline \multicolumn{5}{|l|}{ Treated SAHS } \\
\hline \multicolumn{5}{|l|}{ Sex } \\
\hline Males & 7 & 3.32 & 2.11 & $1.00-4.42$ \\
\hline Females & 1 & 0.56 & 1.80 & $0.11-30.66$ \\
\hline \multicolumn{5}{|l|}{ Age in males } \\
\hline $17-50$ yrs & 1 & 0.24 & 4.21 & $0.59-29.90$ \\
\hline $51-60$ yrs & 2 & 1.05 & 1.91 & $0.48-7.62$ \\
\hline$>60$ yrs & 4 & 2.04 & 1.96 & $0.74-5.23$ \\
\hline Test for trend & & & & $\mathrm{p}>0.20$ \\
\hline
\end{tabular}

SAHS: sleep apnoea/hypopnoea syndrome. 
treatment groups, such as the lower comorbidity registered in those treated by surgery. Although the use of Cox regression tended to reduce this bias, it may not have eliminated it completely. Thirdly, a further possible source of bias arose from the 71 patients who, throughout the follow-up, changed their original treatment cohort and were considered censored thereafter. However, the abandonments principally affected the group of nontreated patients. Thus, it was to be expected that the present analysis in fact tended to underestimate the mortality of the nontreated cohort. Fourthly, the nontreated patients in this study presented more severe SAHS than patients not treated since the advent of nCPAP, who were not included in this analysis. The evolution of these milder SAHS is an objective of large prospective studies currently underway $[1,24]$.

The present results concur with those of previous studies in which mortality in SAHS patients treated with nCPAP was lower than that reported in nontreated patients [12] and similar to that of the general population $[22,23]$. The application of nCPAP suppresses apnoeas, and subsequently eliminates recurrent episodes of hypoxaemia and the cardiovascular consequences associated with them [25]. In the long term, this could contribute to reducing mortality, which in fact occurred in this study, although the nCPAP users may not have been as adherent as their subjective reports indicated [26]. However, the lower mortality registered in the present study in SAHS patients treated with diet or surgery had not been found previously $[12,13]$. In the control PSG, performed in $84 \%$ of these patients, a significant reduction in sleep-disordered breathing and cure of SAHS was observed in $35 \%$, which could have had a similar influence to that of treatment with nCPAP. It should be emphasised that patients who received both treatments maintained a weight lower than that at diagnosis, which has been proved to be an important factor in maintaining the benefits achieved with them [27, 28] and which has been related to the periodic clinical follow-up [28]. Furthermore, the periodic clinical follow-up of these patients permitted the detection of therapeutic failures and establishment of alternative treatment that may have favoured the results of treatment with diet or surgery.

Of the characteristics present at diagnosis of SAHS, age, history of severe COPD, smoking and obesity proved to have a significant impact on mortality of the present cohort. As reported in previous studies $[12,14]$, in the present study the RR of overall and cardiovascular mortality in untreated male SAHS patients increased in the youngest, and was higher in those $<50 \mathrm{yrs}$ of age. The poor prognosis of the SAHS-COPD association had previously been reported, even in patients treated with nCPAP $[22$, 23]. The greater hypoxaemia present in patients with COPD and SAHS [29] or the incidence of severe respiratory complications [11] could be responsible for the mortality in these patients. Furthermore, the trend of BMI to increase SAHS-related mortality, together with the benefits reported with diet treatment, emphasises the importance of weight reduction as a complementary measure in the management of these patients.

By contrast, AHI at diagnosis, AHT and sex did not influence survival in the present study. In the case of AHI, an index usually employed to quantify SAHS severity and related in previous studies to mortality in these patients $[12,14]$, the fact of its being homogeneously raised in the cohort in this study and its modification by the treatments applied could have masked its importance. In the case of AHT, despite the existence of epidemiological studies that point to SAHS as a causal factor of diurnal AHT [4, 5], study of the adverse effect of blood pressure in these patients may require analysis of its nocturnal behaviour [3, 30]. Finally, although particular characteristics of SAHS have been described in females [31] and a preliminary study pointed to a possible increase in mortality [32], no differences were found according to sex.

In conclusion, the authors found an increase in mortality in nontreated sleep apnoea/hypopnoea syndrome patients compared with the general population, with patients under 50 being at greatest risk. Furthermore, a decrease in this mortality was observed in patients receiving sleep apnoea/hypopnoea syndrome treatment. These results underline the need for early detection and treatment of sleep apnoea/hypopnoea syndrome and its subsequent clinical follow-up which permits detection of therapeutic failures.

Acknowledgements. The authors would like to thank Mortality Registry of Catalonia for providing mortality data, Laboratori de Bioestadística i Epidemiologia, Universitat Autonoma de Barcelona, for advice in the analysis and $\mathrm{C}$. O'Hara for help with the English translation.

\section{References}

1. Young T, Palta M, Dempsey J, Skatrud J, Weber S, Badr S. The occurrence of sleep-disordered breathing among middle-aged adults. $N$ Engl J Med 1993; 328: $1230-1235$

2. Duran J, Esnaola S, Rubio R, Iztueta A. Obstructive sleep apnea-hypopnea and related clinical features in a population-based sample of subjects aged 30 to $70 \mathrm{yr}$. Am J Respir Crit Care Med 2001; 163: 685-689.

3. Davies RJ, Crosby J, Vardi-Visy K, Clarke M, Stradling JR. Non-invasive beat to beat arterial blood pressure during non-REM sleep in obstructive sleep apnoea and snoring. Thorax 1994; 49: 335339.

4. Nieto FJ, Young TB, Lind BK, Shahar E, Samet JM, Redline S. Association of sleep-disordered breathing, sleep apnea, and hypertension in a large communitybased study. Sleep Heart Health Study. JAMA 2000; 283: 1829-1836.

5. Peppard PE, Young T, Palta M, Skatrud J. Prospective study of the association between sleep-disordered breathing and hypertension. N Engl J Med 2000; 342: 1378-1384

6. Hung J, Whitford EG, Parsons RW, Hillman DR. Association of sleep apnoea with myocardial infarction in men. Lancet 1990; 336: 261-264. 
7. Mooe $\mathrm{T}$, Rabben $\mathrm{T}$, Wiklund $\mathrm{U}$, Franklin KA, Eriksson P. Sleep-disordered breathing in men with coronary artery disease. Chest 1996; 109: 659-663.

8. Parra O, Arboix A, Bechich S, Garcia-Eroles L, Montserrat JM, Lopez JA. Time course of sleeprelated breathing disorders in first-ever stroke or transient ischemic attack. Am J Respir Crit Care Med 2000; 161: 375-380.

9. Teran-Santos J, Jimenez-Gomez A, Cordero-Guevara J. The association between sleep apnea and the risk of traffic accidents. Cooperative Group BurgosSantander. N Engl J Med 1999; 340: 847-851.

10. Bradley TD, Rutherford R, Grossman RF, Lue F, Zamel N, Moldofsky H. Role of daytime hypoxemia in the pathogenesis of right heart failure in the obstructive sleep apnea syndrome. Am Rev Respir Dis 1985; 131: 835-839.

11. Fletcher EC, Shah A, Qian W, Miller CC III. "Near miss" death in obstructive sleep apnea: a critical care syndrome. Crit Care Med 1991; 19: 1158-1164.

12. He J, Kryger MH, Zorick FJ, Conway W, Roth T. Mortality and apnea index in obstructive sleep apnea. Experience in 385 male patients. Chest 1988; 94: 9-14.

13. Partinen M, Jamieson A, Guilleminault C. Long-term outcome for obstructive sleep apnea syndrome patients. Mortality. Chest 1988; 94: 1200-1204.

14. Lavie P, Herer P, Peled R, Berger I, Yoffe N, Zomer J. Mortality in sleep apnea patients: a multivariate analysis of risk factors. Sleep 1995; 18: 149-157.

15. Sullivan CE, Issa FG, Berthon-Jones M, Eves L. Reversal of obstructive sleep apnoea by continuous positive airway pressure applied through the nares. Lancet 1981; 1: 862-865.

16. Engleman HM, Martin SE, Deary IJ, Douglas NJ. Effect of continuous positive airway pressure treatment on daytime function in sleep apnoea/hypopnoea syndrome. Lancet 1994; 343: 572-575.

17. Rechtschaffen A, Kales A. A manual of standardized terminology, techniques and scoring system for sleep stages of human subjects. NIH publication No. 204. Bethesda, MD, 1968.

18. Montserrat JM, Amilibia J, Barbe F, Capote F, Duran J, Mangado NG. Tratamiento del síndrome de apnea-hipopnea del sueño. Arch Bronconeumol 1998; 34: 204-206.

19. ICD-9 (International Classification of Diseases. 9th Revision). Geneva, Switzerland, World Health Organization, 1976.

20. Breslow NE, Day NE. Statistical methods in cancer research. Lyon, International Agency for Research on Cancer, 1987.
21. Institut d'Estadística de Catalunya, Generalitat de Catalunya, 2001. http//www.idescat.es.

22. Chaouat A, Weitzenblum E, Krieger J, Sforza E, Hammad H, Oswald M. Prognostic value of lung function and pulmonary haemodynamics in OSA patients treated with CPAP. Eur Respir J 1999; 13: 1091-1096.

23. Veale D, Chailleux E, Hoorelbeke-Ramon A, ReybetDegas O, Humeau-Chapuis MP, Alluin-Aigouy F. Mortality of sleep apnoea patients treated by nasal continuous positive airway pressure registered in the ANTADIR observatory. Association Nationale pour le Traitement A Domicile de 1'Insuffisance Respiratoire chronique. Eur Respir J 2000; 15: 326-331.

24. Quan SF, Howard BV, Iber C, Kiley JP, Nieto FJ, O'Connor GT. The Sleep Heart Health Study: design, rationale, and methods. Sleep 1997; 20: 1077-1085.

25. Podszus T, Greenberg H, Charf SM. Influence of sleep state and sleep-disordered breathing on cardiovascular function. In: Saunders NA, Sullivan CE, eds. Sleep and Breathing. New York, Marcel Dekker Inc., 1994; pp. $257-310$.

26. Alarcon A, Leon C, Maimo A, Barbe F, Agusti AG, Rodriguez-Roisin R. Compliance with nasal continuous positive airway pressure (CPAP) treatment in sleep apnoea-hypopnoea syndrome. Arch Bronconeumol 1995; 31: 56-61.

27. Larsson LH, Carlsson-Nordlander B, Svanborg E. Four-year follow-up after uvulopalatopharyngoplasty in 50 unselected patients with obstructive sleep apnea syndrome. Laryngoscope 1994; 104: 1362-1368.

28. Sampol G, Muñoz X, Sagales MT, Marti S, Roca A, Dolors de la Calzada M. Long-term efficacy of dietary weight loss in sleep apnoea/hypopnoea syndrome. Eur Respir J 1998; 12: 1156-1159.

29. Chaouat A, Weitzenblum E, Krieger J, Ifoundza T, Oswald M, Kessler R. Association of chronic obstructive pulmonary disease and sleep apnea syndrome. $\mathrm{Am}$ J Respir Crit Care Med 1995; 151: 82-86.

30. Jennum P, Wildschiodtz G, Christensen NJ, Schwartz T. Blood pressure, catecholamines, and pancreatic polypeptide in obstructive sleep apnea with and without nasal continuous positive airway pressure (nCPAP) treatment. Am J Hypertens 1989; 2: 847-852.

31. O'Connor C, Thornley KS, Hanly PJ. Gender differences in the polysomnographic features of obstructive sleep apnea. Am J Respir Crit Care Med 2000; 161: 1465-1472.

32. Young T, Finn L. Epidemiological insights into the public health burden of sleep disordered breathing: sex differences in survival among sleep clinic patients. Thorax 1998; 53: Suppl. 3, S16-S19. 